\title{
FUNGSI DAN MAKNA LINGGA DALAM AJARAN AGAMA HINDU
}

I Made Suta ${ }^{a}$

Fakultas Dharma Duta

Institut Hindu Dharma Negeri Denpasar

\begin{abstract}
Hinduism is a religion that has given birth to a very complex culture in the field of astronomy, agricultural science, philosophy and other sciences. Likewise from this culture gave birth to worship facilities in the form of ancient relics, one of which was Lingga.

Lingga is a symbol of fertility offered by the Indus valley civilization which is mainly associated with Shiva worship. Lingga can mean the manifestation of Lord Shiva which is described as Phalus which is usually placed above Yoni who describes men and women (Lingga-Yoni).

The problem examined in this paper is how the function and meaning of Linga according to Hinduism in Indonesia. To answer these problems, data collection methods are used; literature studies, documents and observations and assisted with Religion and Symbol theory.

Based on data data, it can be seen that the Lingga function is a religious function, namely strengthening, stabilizing Srddha Bhakti Hindus, then the function of fertility is by worshiping Lord Shiva through the media Lingga to invoke fertility on agriculture. Besides that, through worship Lingga has religious significance and symbolic meaning because Lingga is viewed from the religion as a symbol of worship before Lord Shiva. Lingga is believed to have magical powers so that Hindus draw closer to the presence of Ida Sang Hyang Widhi through the Lingga worship media in religious ceremonies such as piodalan in the Kahyangan Tiga / Jagat Temple. Symbolic meaning is Lingga as the symbol of Purusa (Akasa) and earth (Yoni) symbol of Pradana
\end{abstract}

Keywords

Lingga, Pemujaan, Agama Hindu, Dewa Siwa

\footnotetext{
a made_suta@ihdn.ac.id
} 


\section{PENDAHULUAN}

Agama menyadarkan keyakinan dan kepercayaannya pada ajaran-ajaran yang mengatur hubungan manusia dengan sesamanya, dengan alam dan dengan Tuhan secara sistematis dalam tiga kerangkan dasar, yaitu tattwa (filsafat), susila (etika), dan acara (ritual). Ketiga kerangka dasar ini dalam pelaksanaan termanifestasikan dalam wujud gerak atau aktivitas keagamaan. Ajaran tattwa mengejawantah dalam konsep Panca Sraddha, yaitu lima dasar keyakinan agama Hindu yang terdiri dari keyakinan terhadap adanya Brahman (Tuhan), Atman (roh), Punarbawa (kelahiran kembali), Kharmaphala (hukum sebab-akibat), dan Moksa (kebebasan abadi, yaitu manunggal dengan Tuhan). Susila atau etika diaplikasikan melalui Tri Kaya Parisudha, yaitu tiga macam prilaku yang disucikan, yaitu kayika, wacika dan manacika. Selanjutnya acara (upacara atau ritual) direfleksikan dalam wujud Panca Yadnya yaitu lima macam kegiatan spiritual yang dilakukan dengan tulus ikhlas dan bhakti dalam bentuk ritual. Panca Yadnya itu terdiri dari Dewa Yadnya, Pitra Yadnya, Rsi Yadnya dan Bhuta Yadnya

Sarana pemujaan di Indonesia sangat banyak dijumpai, baik berupa peninggalan-peninggalan kuno seperti candi, arca, pratima, barong yang tujuannya sebagai alat atau sarana mengkonsentrasikan pikiran untuk melakukan pemujaan kehadapan Ida Sang Hyang Widhi Wasa. Salah satu peninggalan yang digunakan sebagai sarana pemujaan adalah Lingga. Lieber dalam Ambarawati (1997: 52) menyebutkan di India Selatan dan Tengah ( Madya Pradesh), pemujaan melalui media Lingga sangatlah populer bahkan ada suatu sekte khusus yang memuja Lingga yang menamakan dirinya Sekte Linggayat. Pada umumnya mereka memakai kalung dengan hiasan beberapa buah Lingga. Lingga merupakan lambang kesuburan yang diperlihatkan oleh peradaban Lembah Indus. Hal ini dilarang oleh Bangsa Indo Arya, tetapi kemudian timbul kembali dan khususnya di hubungkan dengan Siwa. Lingga dapat juga berarti sebagai perwujudan Dewa Siwa sebagai sebuah phallus dan biasanya phallus (Lingga) ditempatkan diatas vulva (yoni). Yoni berarti simbol alat kelamin wanita, atau vulva sebagai simbol unsur wanita. Yoni dalam bentuk cincin batu (ring stone) ditemukan pada peradaban Lembah Indus. Selanjutnya yoni dipuja khususnya oleh Sekte Sakta sebagai unsur Sakti dan seringkali digambarkan didalam susunan Lingga.

Soemadio dalam Ambarawati (1997 : 53) menyebutkan Lingga yang tertua di Indonesia dapat diketahui dari Prasasti Canggal yang berasal dari halaman percandian diatas gunung Wukir di Kecamatan Sleman. Prasasti ini ditulis dengan huruf Pallawa dan berbahasa Sansekerta yang berangka tahun 654 Caka (732 M). Dari prasasti ini diketahui bahwa pada tahun 732 M Raja Sanjaya yang beragama Siwa telah mendirikan sebuah Lingga di atas bukit.

Lingga Yoni di Bali sangat banyak ditemukan, yang memberikan petunjuk bahwa pada masa lampau di Bali ruparupanya pernah berkembang Sekte Pasupati, yaitu salah satu sekte dalam agama Hindu. Pada saat ini Sekte Pasupati sebagai salah satu kelompok tersendiri tidak berkembang lagi di Bali. Dalam salah satu ajaran Pasupati 
disebutkan, bahwa pengikut Siwa adalah Kusika, Gorgya, Mitra, Kaurasya, dan Patanjala. Menurut beberapa literatur Bali pengikut ini muncul dibawah Panca Kosika. Pemujaan terhadap Lingga atau Phallus dalam bentuk yang lebih alamiah sebagai lambang Siwa merupakan ciri atau tanda khas Pasupati yang lebih kuno (Goris, 1974:14-15).

Lingga Yoni dalam huruf Bali, digambarkan sebagai Ongkara, nada sebagai Lingga (phallus), arda chandra sebagai lambang alat kelamin wanita dan windu sebagai lambang penyatuan antara unsur laki-laki dengan wanita dan dengan demikian kata Ong adalah sebagai simbol Siwa. Lingga dapat juga sebagai simbol kesuburan yang diperlihatkan pada peradaban lembah Indus pada masa 500 atau 200 SM (Goris,1974:14-15).

Agama Hindu sangat kaya dengan berbagai simbol yang dapat menggetarkan kalbu, dan berusaha untuk memahami makna yang terkandung dibalik simbol-simbol tersebut. Simbol-simbol tersebut merupakan media bagi umat Hindu untuk mendekatkan diri dengan Sang pencipta. Simbol-simbol dalam agama Hindu sangat terkait dan tidak dapat dipisahkan dengan ajaran ketuhanan (teologi Hindu). Simbol-simbol tersebut berupa arca atau pretima untuk dewadewa, wahana dewata atau kendaraan dewa-dewa, bangunan suci sebagai stana untuk memujanya. Bangunan suci salah satunya adalah melalui media Lingga. Pemujaan kepada Sang Hyang Siwa melalui Lingga sangat populer bagi umat Hindu di India demikian pula di Indonesia.

PEMBAHASAN

Pengertian Lingga
Ambarawati (1997 : 54 Lingga Yoni di Pura Puseh Babahan Linga Yoni adalah sebagai lambang kesuburan, yaitu dengan cara menyiramkan air pada Lingga dan kemudian air yang mengalir melalui ceret yoni itu ditampung dan selanjutnya disiramkan pada tanaman padi atau tanaman lainnya. Disamping itu dengan adanya temuan Lingga Yoni tersebut ternyata Desa Babahan, Penebel merupakan desa kuno. Temuan lain yang menyatakan Desa Babahan, penebel sebagai situs kuno adalah peninggalan dari masa prasejarah, yaitu peninggalan tradisi megalitik berupa papan batu di Pura Puseh Babahan.

Astawa (2009: 46-48), penelitiannya mengenai Arca di Pura Puseh, Banjar Lebah, kecamatan Payangan, memaparkan di pura tersebut terdapat beberapa jenis Lingga yakni: 1). Lingga Yoni yang terdiri dari tiga bagian yaitu bagian bawah berbentuk segi empat (Brahmabhaga), bagian segi delapan (Wisnubhaga) dan bagian bulat (Siwabhaga), 2). Lingga Ganda yaitu dua lingga dalam satu lapik dan dibelakangnya terdapat sandaran, 3). Lingga Semu yaitu yang bentuknya hanya terdiri dari bagian bulat dengan lapik berbentuk segi empat di bagian bawah. Semua jenis Lingga yang ditemukan di Pura Puseh ini terbuat dari batu padas. Lingga biasanya berpasangan dengan Yoni sebagai lambang kesuburan, karena air yang disiramkan pada Lingga mengalir melalui saluran Yoni ditampung dengan suatu benda atau alat kemudian dipercikkan kepada pemujanya dan dapat juga dipercikkan di sawah maupun ladang. Lingga Yoni juga sebagai lambang laki perempuan (Purusa-Predana).

$$
\text { Aryatna (2010), dalam }
$$

penelitiannya berjudul "Fungsi Dan Makna Pura Pesimpangan Pulaki Sakti 
Sebagai Pura Swagina Di Desa Kaliakah, Kecamatan Negara, Kabupaten Jembrana". Dalam karya ilmiah ini diuraikan tentang Pura Pesimpangan Pulaki Sakti merupakan tempat suci bagi umat Hindu di Desa Kaliakah yang disungsung atau dipuja oleh Krama Subak yang mempunyai kepentingan sama berhubungan dengan pertanian. Pura ini memiliki fungsi sebagai tempat persembahyangan bagi Umat Hindu untuk melakukan Upacara Neduh atau upacara memohon hujan jika para petani kekurangan air pada saat menggarap sawahnya dan juga sebagai tempat melukat atau penyucian bagi orang yang terkena penyakit gerubug atau kacacar. Pura Pesimpangan Pulaki Sakti memiliki beberapa makna yaitu makna religius, makna seni (estetika) dan makna simbolis.

Wiana (2009 : 1-36), dalam buku

Pura Besakih Hulunya Pulau Bali menguraikan tentang asal-usul istilah pura di Bali dan menguraikan secara jelas keberadaan Pura Besakih dan menjelaskan komplek pura yang ada di Besakih serta menjelaskan lima fungsi Pura Besakih yaitu sebagai Huluning Bali Rajya, Pura Rwa Bhineda, Pura Sad Winayaka, Pura Padma Bhuwana dan sebagai lambang alam atas dan alam bawah. Pura secara umum berfungsi sebagai tempat pemujaan, pura sebagai tempat suci dan pura sebagai hasil budaya spiritual Hindu.

Titib (2003), dalam buku Teologi dan Simbol-Simbol Dalam Agama Hindu, buku ini membahas terkait dengan pengertian, struktur, makna filosofis pura dan bangunan suci, dan perkembangan pura di Bali termasuk fungsi serta pengelompokannya. Dalam buku ini juga terdapat penjelasan mengenai berbagai macam simbolsimbol suci Agama Hindu.

\section{Konsep Lingga}

Mardiwarsito dalam Ambarawati (1997: 52), Kata Lingga berasal dari bahasa Sansekerta disamping arti yang lainnya Lingga berarti "tanda padanan Phallus, kemaluan laki-laki" . Lingga antara lain berarti simbol atau lambang jenis kelamin laki-laki. Media dalam Kamus Besar Bahasa Indonesia (1988) merupakan alat, sarana, perantara atau penghubung. Sedangkan pemujaan berasal dari kata puja, pemujaan berarti proses, cara, perbuatan memuja dan penghormatan kepada dewa-dewa.

Sarana pemujaan dalam agama hindu tidak bisa lepas dengan symbol sebagai perwujudan yang dipuja. Simbol paling tidak memenuhi empat perangkat yakni:1). Simbol adalah kontruksi yang berbentuk kepercayaan dan biasanya merupakan inti dari agama,2). Simbol adalah evaluasi berupa penilaian moral yang sarat dengan nilai, norma dan aturan, 3). Simbol merupakan kognisi berupa pengetahuan yang dimanfaatkan manusia untuk memperoleh pengetahuan tentang realitas dan keteraturan agar manusia lebih memahami lingkungan, 4). Simbol merupakan ekspresi berupa pengungkapan perasaan (Triguna, 2000:35).

Simbol berfungsi memimpin pemahaman subjek kepada objek. Simbol dapat membangkitkan emosi serta mendorong orang untuk berkreasi. Manifestasi serta karakteristik simbol tidak terbatas pada isyarat fisik, tetapi dapat juga berwujud penggunaan katakata yakni, simbol suara yang mengandung arti bersama serta bersifat standar. Juga dikatakan suatu 
pendekatan yang memandang bahwa manusia yang berinteraksi dengan lingkungan hidupnya tidak terlepas dari simbol, karena simbol-simbol juga dapat membangkitkan emosi serta dorongan orang untuk berkreasi (Triguna, 2000:7)

Siwananda menjelaskan tentang manfaat simbol sebagai berikut: "Bagaimanapun kecerdasan seseorang ia tidak dapat berkonsentrasi tanpa bantuan suatu simbol pada awalnya, dalam rangka ia memuja tujuan (Brahman), simbol bermanfaat bila dilihat dari sudut pandang yang benar. Simbol akan memainkan suatu bagian yang sangat penting dalam kehidupan material dan spiritual. Walaupun kelihatannya sangat ilmiah dan efektif. Penggunaan sarana berupa simbol sangatlah dibutuhkan oleh umat dalam meningkatkan rasa bhaktinya kepada Brahman. Mengingat keterbatasan yang dimiliki oleh manusia biasa, maka ia tak akan berhubungan langsung atau memuja Brahman tanpa menggunakan simbol karena mereka sudah melatih diri sejak lama melalui ajaran yoga atau meditasi yang rutin, sehingga mereka bisa mencapai suatu kesidian.

\section{Fungsi Lingga}

Fungsi symbol ( Lingga ) dalam Agama Hindu meliputi beberapa aspek: 1). Meningkatkan dan memantapkan sraddha ( keimanan atau keyakinan mendalam) umat dalam rangka menumbuhkan bhakti ( ketaqwaan), yang akan membentuk kepribadian umat manusia dengan moralitas tinggi yang pada akhirnya meningkatkan akhlak luhur masyarakat; 2). Menumbuh kembangkan dan tetap terpeliharanya nilai seni budaya baik melalui seni arca, seni lukis dan seni kriya, lainnya yang dibuat tidak menyalahi ketentuan kitab
Silparasatra dimaksud; 3). Memupuk kebersamaan dikalangan umat Hindu dalam mewujudkan sarana pemujaan, utamanya dalam kaitan dengan sakralisasi dan memfungsikan simbolsimbol yang dibuat tersebut. Simbol dalam agama Hindu sangat bermanfaat, karena merupakan media untuk mendekatkan diri kepada Tuhan Yang Maha Esa, dan menumbuhkan rasa bhakti dalam diri pribadi umat (Titib, 2003:66).

Upacara religi biasanya menggunakan berbagai macam sarana dan peralatan, tempat atau gedung pemujaan, patung dewa, patung orang suci gambelan suci. Para pelaku upacara sering kali harus menggunakan pakaian yang juga dianggap mempunyai sifat suci (Koentjaraningrat, 1987 :91). Tylor dalam Koentjaraningrat, 1997:194-195, mengenai asal mula dan inti dari suatu unsur universal seperti religi atau agama, menyebabkan bahwa prilaku yang bersifat religi itu terjadi karena: 1). Manusia mulai sadar akan adanya konsep roh; 2). Manusia mengakui adanya berbagai gejala yang tidak dapat dijelaskan dengan akal sehat; 3). Keinginan manusia untuk menghadapi berbagai krisis yang senantiasa dialami manusia dalam daur hidupnya; 4). Kejadian-kejadian luar biasa yang dialami manusia dialam sekelilingnya. Disamping asal mula dari religi adalah kesadaran manusia akan konsep roh, yang sebaliknya disebabkan oleh dua hal yaitu:

1. Perbedaan yang tampak antara bendabenda yang hidup dan benda-benda yang mati. Dengan demikian gerak daya alam (yaitu hidup) disebabkan oleh suatu kekuatan yang berada disamping tubuh jasmaninya, yakni jiwa yang kemudian lebih khusus disebut roh. 
2. Pengalaman bermimpi, dalam mimpinya manusia melihat dirinya berada ditempat-tempat lain selain tempat ia tidur. Manusia mulai membedakan antara tubuh jasmani yang berada di tempat tidur dan bagian lain dirinya, yaitu jiwanya (rohnya) yang pergi ketempat lain.

Menurut Dukheim dalam Koentjaraningrat (1997: 201-202) menguraikan dasar-dasar religi menjadi lima komponen religi yaitu: 1). Emosi keagamaan (getaran jiwa) yang menyebabkan bahwa manusia didorong untuk berprilaku keagamaan; 2). Sistem kepercayaan atau bayangan-bayangan manusia tentang bentuk dunia, alam gaib, hidup, maut, dan sebagainya; 3 ). Sistem ritus dan upacara keagamaan yang bertujuan mencari hubungan dengan dunia gaib berdasarkan sistem kepercayaan tersebut ;4). Kelompok atau kesatuan-kesatuan sosial yang mengkonsepsikan dan mengaktifkan religi berikut sistem upacara-upacara keagamaan; 5). Alat-alat fisik yang digunakan dalam ritue dan upacara keagamaan.

Pemujaan tidak hanya menandakan identitas keagamaan, tetapi lebih dari pada itu pemujaan merupakan pangejawantahan ajaran Agama Hindu itu sendiri. Telah disadari pemujaan melalui media Lingga sebagai simbolik yang digunakan untuk melakukan sujud bhakti kehadapan Ida Sang Hyang Widhi Wasa (Brahman) dan manifestasi-Nya secara tulus ikhlas yang tidak terikat kepada hasil. Sehingga Lingga sebagai media pemujaan memiliki nilai-nilai Tattwa, Etika dan upacara yang mampu menciptakan keseimbangan sekala dan niskala terhadap umat hindu yang dapat meningkatkan sradha dan bhakti.
Masyarakat Hindu dalam melaksanakan ketiga kerangka dasar ( Tatwa.Susila dan Upacara ) diimplementasikan kedalam berbagai pelaksanaan, ajaran tattwa mengejawantah dalam konsep Panca Sraddha, yaitu lima dasar keyakinan agama Hindu yang terdiri dari keyakinan terhadap adanya Brahman (Tuhan), Atman ( roh), Punarbawa (kelahiran kembali), Kharmaphala (hukum sebabakibat), dan Moksa (kebebasan abadi, yaitu manunggal dengan Tuhan). Susila atau etika diaplikasikan melalui Tri Kaya Parisudha, yaitu tiga macam prilaku yang disucikan, yaitu kayika, wacika dan manacika. Selanjutnya acara (upacara atau ritual) direfleksikan dalam wujud panca yadnya yaitu lima macam kegiatan spiritual yang dilakukan dengan tulus ikhlas dan bhakti dalam bentuk ritual Panca Yadnya terdiri dari Dewa Yadnya, Rsi Yadnya, Pitra Yadnya, Manusa Yadnya, dan Bhuta yadnya (Sokaningsih, 2007:3).

Panca Yadnya masing masing dilaksanakan dengan berbagai kegiatan oleh masyarakat hindu yaitu:. (1). Kegiatan Dewa Yadnya dilaksanakan dengan melakukan pemujaan terhadap Ida Sang Hyang Widhi Wasa ( Tuhan Yang Maha Esa) yang merupakan pencipta seluruh alam semesta, membuat sesajen untuk persembahan, memelihara bangunan suci tempat melaksanakan pemujaan dan mempelajari dan mengamalkan ajaran-ajaran suci-Nya. (2). Pelaksanaan Rsi Yadnya dilakukan dengan usaha yang bersifat positif atau kebaikan kepada para pendeta atau orang suci agama Hindu sesuai dengan kemampuan yang ada. Salah satu pelaksanaan Rsi Yadnya yang dilakukan oleh Masyarakat hindu adalah mentaati dan mengamalkan ajaran-ajaran para 
sulinggih karena merupakan guru kerohanian umat Hindu. (3). Manusa Yadnya merupakan korban suci yang dilaksanakan mulai dari bayi masih didalam kandungan sampai akhir hidupnya, yang bertujuan untuk mensucikan lahir dan bhatin. Masyarakat himdu melaksanakan kegiatan Manusa Yadnya salah satunya upacara pagedonggedongan yaitu bayi masih dalam kandungan agar dapat membersihkan serta memohon keselamatan jiwa dan raga si bayi agar nantinya dapat berguna bagi masyarakat dan keluarga. (4). Pelaksanaan Pitra Yadnya dilakukan dengan rasa hormat kepada sesama dan juga kepada orang tua. Manusia diwajibkan untuk menghormati sesama, baik tamu, orang tua, orang-orang suci, maupun para dewa. Sikap hormat kepada orang tua merupakan salah satu pelaksanaan Pitra Yadnya disamping upacara ngaben setelah mereka meninggal.(5). Pelaksanaan Bhuta Yadnya yakni dengan melaksanakan atau mempersembahkan upakara segehan, tawur atau caru sebagai upacara keselamatan kepada para bhuta. Sukrawati (2010:111) menyebutkan tujuan upacara Bhuta Yadnya yaitu : untuk memelihara kesejahtraan dan ketentraman alam semesta, sebagai wujud rasa terima kasih kehadapan Tuhan, para dewa, leluhur dan unsur kekuatann alam yang secara filosofis menggunakan tumbuh-tumbuhan serta binatang/hewan dalam upacara Bhuta Yadnya yang bertujuan untuk pembebasan dan peningkatan terhadap jiwanya, untuk mengusir roh-roh jahat dan kekuatan alam yang mengganggu kehidupan manusia.

Berdasarkan Purana Hyangning Alas yaitu purana yang terdapat di Pura Kancing Gumi menyebutkan:
"Hana mwah linging Dewa Purana, ri huwus metu ikang niladahana, tan kaluputtan katuging linuh, ngardi ikang bhumi anyungsang, kawuwuhin hudan madres katiba mareng prethiwi, laminya kalih candra wusana, blabur mageng tan papegatan, dadita Sanghyang Rudrapati asru masabda ri sang pemedek "lah kita rengenakna para wateking dewata sadaya, iki pawarahing hulun lumarapan antuk sastra Lokanatha Ogan Lupyan, apan kita huwus sphatika weruh apan dibya caksu ika ngaran, tucapa heneng Bangsul wali pulina sighra tumedun ri mangke tattwa ingaranan Dewa Purana, ika pinaka sarana ri tingkahing para dewata,tinuting titahing Hyanging Pasupati, Kasaksenana dening sanghyang Siwaditya, anaburaken ikang amertha ring jagat Windhumaya, nulya angdadi Lingga, pinaka tedungning jagat ika, pancering Bali Pulina, Maka wekasan Hyang Gunung Alas, Hyang Kancing Gumi, ngaran. Huwus Lama Ikang Jagat Bangsul tan kajamah mwang kacemerin dening sarupaning janma manusa, suwung sepa sepi asepah samun tan hana ikang ngawengku Bali Pulina" Mangkana kawuwusannya duking mangkana ring Bangsul huwus samya mangdani wana, wetning tan hana manusa ring Bangsul".

Terjemahannya :

Ada lagi ucapan sastra Dewa Purana, sesudah ada bencana kobaran api, gempa tiada henti, Pulau Bali seperti goyang (tidak menentu), hujan deras dua bulan, 
tiada henti, lalu kemudian ada ucapan dari Sanghyang Rudrapati , diberikan kepada Para Dewata :" Hai Para Dewata semua, seperti yang ada dalam sastra Ogan Lupyan (aji Lokanatha), para dewa semua sudah mengetahui karena terjadi bencana, supaya secepatnya pergi ke Bali, Dewa Purananya harus dibawa, itu perintah dari Sanghyang Pasupati yang disaksikan oleh Sanghyang Siwaditya, menaburkan sumber kehidupan yang makmur berupa Lingga, sebagai pelindung bumi, sebagai penguat Bumi Bali, yang bernama Hyang Gunung Alas, di sebut Hyang Kancing Gumi (Hyang $=$ Pura) karena wilayahnya ditinggalkan oleh penduduk, tidak ada yang menempati wilayah itu, oleh karena itu kembali menjadi hutan. Oleh karena tidak ada manusia di Bali.

(Sumber :Purana Pura Kahyangan Jagat Kancing Gumi, 2005:7-8)

Dalam purana ini secara jelas menyatakan bahwa karena terjadinya bencana sehingga Dewa Rudrapati mengutus Para Dewa untuk ke Bali memperbaiki keadaan yang tidak baik karena bencana, untuk menyelamatkan Bumi Bali atas perintah Sanghyang Pasupati untuk menebarkan Lingga yang merupakan sumber kemakmuran.

Bentuk Lingga menurut penganut agama Hindu percaya bahwa didunia ada tiga macam cahaya, yaitu matahari, kilat dan api. Ketiga unsur inilah yang kemudian dijadikan dasar pembuatan Lingga yaitu Rudrabhaga (Siwa) pada bagian atas, Visnubhaga pada bagian tengah dan Brahmabhaga pada bagian bawah ( Titib, 2003:274).
Ambarawati (1997: 51) dalam penelitiannya mengenai Lingga Yoni di Pura Puseh Babahan, Kecamatan Penebel, Tabanan menyebutkan Lingga Yoni yang terdapat pada pelinggih itu berjumlah tiga buah dan bagian bawah dari yoni itu tertanam, sedangkan bagian bawah Lingga (segi empat) dimasukkan pada lubang Yoni. Tiga buah Lingga yang ditemukan terdiri atas bagian bulat (Siwabhaga) berukuran $14 \mathrm{~cm}$, bagian segi delapan (Wisnubhaga) berukuran 10,5 cm, dan bagian segi empat (Brahmabhaga) berukuran $25 \mathrm{~cm}$.

Astawa (2009 : 47-48), penelitiannya menyebutkan beberapa bentuk Lingga yaitu: (1). Lingga Yoni yang terdiri dari tiga bagian yaitu bagian bawah berbentuk segi empat (Brahmabhaga), bagian segi delapan (Wisnubhaga) dan bagian bulat (Siwabhaga), 2). Lingga Ganda yaitu dua Lingga dalam satu lapik dan dibelakangnya terdapat sandaran, 3). Lingga Semu yaitu yang bentuknya hanya terdiri dari bagian bulat dengan lapik berbentuk segi empat di bagian bawah. Semua jenis Lingga terbuat dari batu padas. Lingga biasanya berpasangan dengan Yoni sebagai lambang kesuburan, karena air yang disiramkan pada Lingga mengalir melalui saluran Yoni ditampung dengan suatu benda atau alat kemudian dipercikkan kepada pemujanya dan dapat juga dipercikkan di sawah maupun ladang. Lingga Yoni juga sebagai lambang laki perempuan (Purusa-Predana).

Lingga merupakan aspek sekunder dari lambang kelaki-lakian Siwa disamping yoni sebagai lambang kewanitaan Dewi Parwati. Aspek utama Lingga melambangkan api atau cahaya sebagai manifestasi dari kekuatan dan kekuasaan, sedangkan yoni adalah 
lambang bumi. Api dan bumi merupakan dua hal yang saling bertentangan, ibarat arus listrik positif dan negatif", bila keduanya dipertemukan sama halnya pertemuan laki-laki dan wanita, keduanya akan mendatangkan arus atau energi (Titib, 2003:273).

Lingga adalah suatu bangunan yang dipergunakan sebagai media untuk memuja Tuhan dalam manifestasinya sebagai Dewa Siwa. Lingga ditinjau dari segi bentuknya merupakan lambang Purusa dan Pradana. Fungsi Lingga adalah sebagai media untuk memohon kesuburan pertanian kepada Tuhan. Tri murti merupakan purusa yang merupakan jiwa atau unsur rohani yang menjadi sumber kehidupan, sedangkan yoni merupakan lambang predana yang pada hakekatnya adalah lambang alam ciptaan Tuhan (Wiana,1993:70-71).

Siwabhaga, Wisnubhaga, dan Brahmabhaga, adalah simbol purusha atau bentuk laki-laki. Yoni adalah simbol dari pertiwi (tanah) melambangkan predana atau wanita. Pertemuan antara purusha dan predana itu merupakan pertemuan positif dan negatif dan dalam kepercayaan umat Hindu pertemuan antara langit dan bumi akan menghasilkan kesuburan.( Putra, 2005 : 30 .

Dalam ikonografi Hindu dikenal dua macam Lingga, yaitu linggacala (dapat dibawa) dan linggacala (yang tidak bergerak atau tidak dapat dipindahkan).

1). Linggacala dalam bentuk kecil, jenis ini umumnya dibuat oleh manusia yang terdiri atas: Mrnmaya, yang dibuat dari tanah liat, Lohaja yaitu Lingga yang menggunakan bahan dasar logam seperti emas, perak, tembaga, besi dan timah. Ratnaja yaitu Lingga yang menggunakan bahan dasar batu-batu mulia seperti
Vaidurya, coral, mutiara, topaz, pusyaraga, zamrud, blue stone. Daruja yaitu Lingga yang menggunakan bahan dasar kayu jenis pohon sami, madhuka, tinduka, khadira, candana,bilva, badara dan devadaru. Sailaja yaitu Lingga yang menggunakan bahan dasar batu pumsila, strisila. Lingga jenis ini umumnya berbentuk kecil. Ksanika yaitu Lingga yang menggunakan bahan dasar nasi, beras, pasir, mentega, kotoran sapi, bunga dan tepung. Bahan dan pembuatan Lingga erat kaitannya dengan tujuan dilakukannya pemujaan. Lingga yang terbuat dari emas bertujuan untuk mendapatkan kekayaan. Lingga yang terbuat dari nasi umumnya digunakan bila pemujanya mengharapkan mendapatkan makanan, terutama nasi. Lingga dengan bahan tanah liat untuk mendapatkan kekayaan, sedangkan Lingga dari kotoran sapi digunakan untuk menghilangkan penyakit. Lingga dengan bahan dasar mentega umumnya untuk memberikan suasana gembira, jika pemuja ingin mendapakan umur panjang maka melakukan pemujaan denga Lingga yang terbuat dari bunga-bungaan. Untuk mendapatkan kebahagiaan Lingga yang dipuja umumnya terbuat dari kayu cendana.

2). Linggacala berdasarkan cara pembuatannya terdiri dari dua macam yaitu, pertama lingga yang bukan dibuat manusia ( tumbuh secara alami), dan lingga yang dibuat manusia. Lingga yang bukan dibuat oleh manusia terdiri dari, Svayambhuva yaitu terjadi dengan sendirinya, Daivika yang dibuat oleh para dewa, umumnya berbentuk seperti api, tangan dalam sikap anjali (menyembah), Ganapa yaitu umumnya berbentuk seperti ketimun, jeruk, apel, dan palem. Arsa yaitu yang dibuat oleh para Rsi 
umumnya berbentuk lonjong dengan ketentuan bagian atas lebih kecil daripada bawahnya. Kedua, Lingga yang dibuat manusia yang terdiri dari, Sarvadesika, Lingga jenis ini panjangnya ditentukan oleh perbandingan dengan sisi ruangan dalam candi. Sarvasama, yang perbandingan antara Rudrabhaga, Visnubhaga, dan Brahmabhaga sama tinggi. Saivadhika, yaitu mempunyai perbandingan panjang, dua bagian bawah sama panjang dan satu bagian bawah lebih panjang. Swastika, jenis Lingga ini mempunyai proporsi semakin keatas semakin panjang (bagian atas terpanjang) dengan perbandingan 2:3:4. Vardamana, jenis Lingga dengan proporsi makin keatas semakin panjang dengan perbandingan 4:5:6, 5:6:7, dan Trairasika, jenis Lingga ini mempunyai proporsi tinggi keseluruhan Lingga dibagi 9 dengan ketentuan perbandingan antara Rudrabhaga: Visnubhaga: Brahmabhaga, 6:7:8 (Titib, 2003:274276).

Setiap bentuk pemujaan memiliki fungsi religius. Sarana pemujaan dengan media Lingga merupakan kepercayaan yang dianut oleh masyarakat hindu. Religi adalah segala tingkah laku manusia untuk mencapai suatu maksud dengan cara menyadarkan diri pada kemauan dan kekuasaan mahluk-mahluk halus seperti, roh, dewa-dewa, dan sebagainya yang menempati alam ini (Koentjaraninggrat, 1997:54).

Ditinjau dari fungsi religius Lingga menyebabkan prilaku umat hindu yang bersifat religi, (1) Masyarakat hindu percaya bahwa Lingga tersebut merupakan stana Hyang Siwa dan sangat disucikan keberadaanya. (2). Melakukan pemujaan melalui media Lingga selalu dilakukan dengan harapan agar senantiasa dilindungi, diberikan kemakmuran oleh Hyang Siwa (Tuhan). (3). Dengan mengetahui bahwa melakukan pemujaan kehadapan media Lingga dapat memberikaen pengaruh yang baik terhadap kehidupan maka masyarakat senantiasa melakukan pemujaan kepada Hyang Siwa melalui media Lingga. (4). Banyak kejadian luar biasa yang di alami oleh masyarakat seperti dilihatnya sinar yang menerangi pemukiman, didapatkannya keris secara tiba-tiba diatas Lingga dan kejadian lainnya. Dapat disimpulkan dengan berbagai pengalaman yang pernah dialami oleh masyarakat sehingga memperkuat, memantapkan Sradha umat dalam rangka menumbuhkan bhakti yang akan membentuk kepribadian masyarakat hindu menjadi lebih baik.

\section{Makna Pemujaan Lingga}

Lingga merupakan salah satu tempat suci bagi masyarakat hindu yang ber makna khusus baik dari segi bangunan, keunikan yang terdapat pada Lingga tersebut maupun upacara keagamaan khususnya untuk Umat Hindu.

Secara umum pelaksanaan pemujaan dengan menggunakan sarana upakaraupakara memiliki makna antara lain : 1). Sebagai lukisan rasa syukur dan terima kasih yang dicetuskan kehadapan Sang Hyang Widhi atas segala anugerah yang telah kita nikmati. 2). Sebagai lukisan permohonan, seperti permohonan umur panjang. 3). Sebagai lukisan permohonan maaf untuk diampuni atas segala kesalahan atau kekeliruan yang telah diperbuat, seperti dilukiskan dalam banten guru piduka. 4). Sebagai sarana untuk melukiskan atau menggambarkan 
secara simbolis wujud Tuhan yang akan dipuja saat itu Adapun makna pemujaan Lingga adalah sebagai berikut,

1) Makna Religious

Lingga ditinjau dari segi religi dapat dianalisis sebagai berikut: (1). Lingga merupakan emosi keagamaan masyarakat yang diyakini sebagai simbol pemujaan kepada Siwa, sehingga dengan demikian masyarakat sangat meyakini Lingga sebagai media pemujaan dengan menggunakan sarana -sarana upacara keagamaan ( upakara banten), media pemujaan terhadap Lingga diwujudkan dalam bentuk pemujaan kepada Siwa pada saat upacara piodalan, rerainan purnama tilem atau dengan kegiatan meditasi. (2). Lingga ditinjau dari segi nilai religi merupakan kepercayaan masyarakat yang mempunyai kekuatan gaib sehingga dengan demikian umat lebih mendekatkan dirinya kepada Tuhan melalui pemujaaan terhadap Lingga. (3). Pemujaan terhadap Siwa disamping diwujudkan dalam bentuk Lingga juga diwujudkan dalam bentuk banten dalam bentuk Siwa Lingga yang mengandung nilai-nilai filosofis berdasarkan teori religi. (4). Kelompok masyarakat yang merupakan satu kesatuan sosial sebagai pengempon suatu tempat pemujaan mengkonsepsikan bahwa Lingga sebagai pusat pemujaaan dengan dipuja dengan menggunakan upakara peras ajengan daksina, upakara dampulan kelanan gong, upakara ulam taluh meguling, upakara telur itik sebanyak enam biji, dan upakara segehan. (5). Lingga selalu digunakan sebagai media pemujaan dalam upacara keagamaan khususnya pada saat piodalan sehingga dengan demikian tampak sekali makna religius Lingga sebagai media pemujaan
(Dukheim dalam Koentjaraningrat 1997: 201-202).

Lingga sebagai media pemujaan memiliki makna religius yang selalu diyakini masyarakat himdu. Lingga itu sendiri yang memiliki fungsi untuk memohon keselamatan, kesuburan, kebahagiaan. Sehingga masyarakat bersifat religius dengan selalu menjaga kesucian areal pura/ tempat suci baik dari benda material yang kotor, pikiran, perkataan, dan perbuatan yang tidak baik sehingga kesucian pura tetap terjaga.

Dengan demikian masyarakat semakin kuat kepercayaanya terhadap keberadaan Lingga yang dapat memberikan efek positif terhadap kehidupan masyarakat hindu khususnya dan masyarakat luas pada umumnya.

2) Makna Simbolis Lingga

Lingga itu merupakan lambang Purusa yang memberikan kehidupan dan tempat Lingga adalah bumi sebagai lambang Predana, Jika Purusa dan predana bersatu akan memberikan efek yang baik bagi kehidupan manusia. Aspek utama Lingga adalah melambangkan api atau cahaya sebagai manifestasi dari kekuatan dan kekuasaan, sedangkan Yoni adalah lambang bumi. Api dan bumi merupakan dua hal yang saling bertentangan ibarat arus listrik positif dan negatif. Bila keduanya dipertemukan akan mendatangkan arus atau energi. Dengan melakukan pemujaan terhadap Lingga masyarakat berharap diberikan keselamatan dan kemakmuran dalam menjalani kehidupan serta Lingga merupakan media penghubung antara pemuja dengan yang di puja yakni Hyang Siwa.

Hiasan padmasana pada bagian
puncak yakni Sang Hyang Acintya 
merupakan simbolis Tuhan Yang Maha Esa (Ida Sang Hyang Widhi Wasa) yang ditempatkan pada puncak bangunan, yang merupakan simbol dari Dewa Siwa dengan tarian Siwa Natyaraja dalam menciptakan alam semesta. Naga membelit bedawang nala simbolis kestabilan dan keseimbangan alam semesta beserta isinya yang ditempatkan didasar bangunan. Burung garuda pada bangunan padmasana di bagian belakang merupakan simbol Dewa Visnu yang sedang membawa Tirta Amerta (Titib, 2003:107-107).

Disamping itu dalam sebuah pura terdapat bangunan Gedong Catu Meres dan Catu Mujung. Gedong Catu Mujung merupakan simbol pemujaan kepada gunung karena gunung merupakan sumber kehidupan, gunung merupakan tempat yang disucikan, sedangkan Gedong Catu Meres merupakan simbol pemujaan yang dilakukan kepada danau atau sumber air. Gedong Catu Meres sebagai media untuk memuja air karena manusia tidak bisa hidup tanpa air sehingga disimbolkan dengan memuja Gedong Catu Meres . Dengan pemujaan ini umat disadarkan agar selalu ingat untuk memelihara alam serta sumber air untuk kelangsungan hidupnya.

Terkait dengan pemujaan Dewa Siwa terdapat patung Nandini yang merupakan simbol kendaraan Hyang Siwa.

Anusasanaparwa 77 dalam Titib (2003 : 286-287) menyebutkan sapi-sapi yang ada di bumi merupakan keturunan Surabhi. Buih susu yang mengalir seperti buih gelombang samudra jatuh di Siwabhumi. Siwa tidak senang hal itu. la membuka mata ketiga dan memperhatikan sapi tersebut. Kobaran api dari mata ketiga Siwa itu menjadikan sapi kulitnya beraneka warna. Sapi tersebut memohon perlindungan kepada Chandra. Kobaran api mata ketiga Siwa juga mengikuti, Ahhirnya Prajapati memohon kepada Siwa untuk menghentikan hal itu, Siwa menghentikan dan menjadi tenang. Prajapati mempersembahkan Seekor sapi jantan untuk tunggangannya. Sejak saat itu kendaraan Dewa Siwa berupa seekor sapi (Nandini), dan Siwa dikenal dengan Nama Vrsabhavahana atau Vrsbhanka.

\section{PENUTUP \\ Simpulan}

Berdasarkan temuan yang telah dipaparkan bahwa keberadaan Lingga sampai saat ini masih tetap dijaga dan dipertahan oleh masyarakat khususnya penganut agama hindu di Indonesia dan umat hindu di Bali terbukti banyak diketemukan tempat suci yang didalamnya terdapat pemujaan Lingga dan Yoni sebagai satu kesatuan sebagai symbol Purusa dan Pradana.

Pemujaan terhadap Lingga dan Yoni oleh umat hindu sebagai symbol perwujudan Dewa Siwa dan Saktinya diyakini berfungsi untuk memohon keselamatan /kerahayuan terhadap macrocosmos dan mikrocosmos dismping itu dapat memberikan kesuburan tanaman dengan memercikan tirtha yng dimohon dari Lingga dengan harapan tanamannya tumbuh subur dan panen yang berlimpah. Selain itu pemujaan Lingga juga berfungsi sebagai pemersatu umat dilihat dari social kemasyarakatanya dan social religius dapat dilihat dari kekhusukan umatdalam melaksanakan pemujaan/persembahyangan secara bersama-sama tanpa melihat tinggi rendah status social diantara mereka. 


\section{Saran}

Umat hindu secara umum dalam meyakini keberadaan Ida SangHyang Widhi dan manifestasi beliau tidak terlepas dengan symbol-simbol yang diyakini sebagai perwujudan Beliau baik berupa arca,patung, Barong, keris, permata/pratima dan sebagainya agar senantiasa menjaga kelestariannya serta kesuciannya agar terhindar dari hal yang tidak diinginkan seperti; pencurian, pelecehan dari orang-orang yang tidak bertanggungjawab.

\section{DAFTAR PUSTAKA}

Ambarawati, Ayu 1997, Seri penerbitan Forum Arkiologi, Denpasar Balai Arkiologi

Aryatna, Nyoman Erna 2010, Fungsi dan Makna Pura Pesimpangan Pulaki Sakti sebagai Pura Swagina Di Desa Kaliakah, Kecamatan Negara, Kabupaten Jembrana".

Gede, Kompiang. 2009. Seri Penerbitan Forum Arkiologi. Denpasar: Balai Arkiologi Denpasar.

Goris, R. 1974. Sekte-sekte di Bali (terjemahan). Jakarta: Bhratara.

Koentjaraningrat. 1987. Sejarah Teori Antropologi I. Jakarta: Universitas Indonesia.

Koentjaraningrat.1997. Antropologi Budaya. Jakarta: Dian Rakyat.

Lukman, A. 1988. Kamus Besar Bahasa Indonesia. Jakarta. Balai Pustaka.

Pudja,G. 2002. Bhagawad Gita (Pancama Veda). Surabaya: Paramita
Putra, I G AG. 1998. Wrhaspati Tattwa. Surabaya: Paramita

Sokaningsih, Ni Made. 2007. Upacara Pemujaan Durga Mahisasura Mardani. Surabaya: Paramita

Titib, I Made. 2003. Theologi dan Simbolsimbol dalam Agama Hindu. Surabaya: Paramita

Triguna, Ida Bagus Gede Yudha. 2000. Teori Tentang Simbol Widya Dharma. Denpasar: Universitas.

Wiana, I Ketut. 2009. Pura Besakih Hulunya Pulau Bali. Surabaya: Paramita 